\title{
Squamous Cell Carcinoma with Horn Formation
}

National Cancer Institute

\section{Source}

National Cancer Institute. Squamous Cell Carcinoma with Horn Formation. NCI

Thesaurus. Code C65179.

A keratinizing squamous cell carcinoma characterized by the presence of horn pearls.

Representative examples include squamous cell carcinomas of the face presenting as a cutaneous horn. 